\title{
DETERMINAN PERMINTAAN EKSPOR KEPITING/RAJUNGAN OLAHAN INDONESIA KE AMERIKA SERIKAT: PENDEKATAN ERROR CORRECTION MODEL
}

\section{Determinants of Demand for Indonesian Export of Processed Crabs to the United States: An Error Correction Model Approach}

\author{
*Estu Sri Luhur ${ }^{1}$, Asnawi ${ }^{2}$, Freshty Yulia Arthatiani ${ }^{1}$, dan Siti Hajar Suryawati ${ }^{1}$ \\ ${ }^{1}$ Balai Besar Riset Sosial Ekonomi Kelautan dan Perikanan \\ Gedung BRSDM KP I Lt. 4, Jalan Pasir Putih Nomor 1 Ancol Timur, Jakarta Utara, Indonesia \\ Telp: (021) 64711583 Fax: 64700924 \\ ${ }^{2}$ Politeknik Ahli Usaha Perikanan, Kampus Bogor \\ Diterima tanggal: 18 Agustus 2020; Diterima setelah perbaikan: 22 Desember 2020; \\ Disetujui terbit: 28 Desember 2020
}

\begin{abstract}
ABSTRAK
Kepiting/rajungan merupakan salah satu komoditas ekspor perikanan yang terus meningkat permintaannya. Penelitian ini bertujuan menganalisis permintaan ekspor kepiting/rajungan olahan Indonesia ke Amerika Serikat sebagai pasar tujuan utama. Data yang digunakan adalah data sekunder, yaitu data harga ekspor kepiting/rajungan Indonesia ke Amerika Serikat, volume produksi kepiting/ rajungan di dalam negeri, dan nilai tukar rupiah terhadap dolar Amerika Serikat. Data tersebut diperoleh dari UN-Comtrade, Kementerian Kelautan dan Perikanan (KKP), dan Badan Pusat Statistik (BPS). Metode analisis data yang digunakan adalah ekonometrika dinamis dengan pendekatan Error Correction Model $(E C M)$. Hasil penelitian menunjukkan bahwa variabel yang memiliki pengaruh terhadap permintaan ekspor kepiting/rajungan Indonesia ke Amerika Serikat pada jangka pendek adalah harga ekspor dan volume produksi di dalam negeri dengan nilai koefisien masing-masing sebesar -0.7818 dan 0.5270. Pada jangka panjang, variabel yang berpengaruh adalah harga ekspor kepiting/rajungan Indonesia ke Amerika Serikat dengan nilai koefisien sebesar - 0.7938. Upaya peningkatan volume ekspor kepiting/ rajungan Indonesia ke Amerika Serikat dapat dilakukan dengan kebijakan melalui usaha nelayan dan perbaikan mekanisme rantai pasok (foodchains) yang berdampak menurunkan harga ekspor kepiting/ rajungan Indonesia ke Amerika Serikat dan perbaikan kualitas produksi kepiting/rajungan di Indonesia. Selain itu, seiring dengan meningkatnya permintaan kepiting/rajungan di Amerika Serikat dapat memberikan peluang bagi Indonesia untuk meningkatkan ekspor kepiting/rajungan ke Amerika Serikat.
\end{abstract}

Kata Kunci: permintaan ekspor, kepiting/rajungan, perikanan, Amerika Serikat, error correction model

\begin{abstract}
Crab is one of fishery export commodity that has continuing increase in demand. This study aimed to analyze demand for Indonesian processed crab exports to the United States as the main destination market. Data used are secondary data, namely data on export price of Indonesian crabs to the United States, the volume of domestic crab production, and exchange rate of the rupiah against the US dollar. Data was obtained from UN-Comtrade, Ministry of Marine Affairs and Fisheries (KKP), and Central Statistics Agency (BPS). Data were analyzed using dynamic econometrics method with the Error Correction Model (ECM) approach. Variables of the study are export price of Indonesian crab to the United States, production volume of crab in Indonesia, and exchange rate of rupiah against United States dollar. The results showed that export prices and domestic production volume are variables influencing demand for Indonesian crab exports to the United States in the short term with coefficient value of -0.7818 and 0.5270 respectively. In the long term, the influencing variables is domestic production volume with coefficient value of 0.7938 . Export volume to the United States could be increased through policy on fishing effort and supply chain mechanism improvement that resulted in the decrease of export prices and improved quality of the crabs. In addition, the increasing number of crab demand in the United States provides opportunities for Indonesia to increase crab exports to the United States.
\end{abstract}

Keywords: export demand, crabs, fisheries, United State of America, error correction model 


\section{PENDAHULUAN}

Salah satu komoditas utama perikanan adalah kepiting/rajungan yang memiliki nilai ekonomi tinggi. Hal ini ditunjukkan oleh volume produksinya yang menunjukkan tren pertumbuhan dalam 3 (tiga) tahun terakhir. Pada tahun 2017, volume produksi kepiting/rajungan mencapai 169.795 ton atau naik $74 \%$ dibandingkan tahun sebelumnya (KKP, 2019). Sementara itu, volume produksi kepiting/ rajungan pada tahun 2017 juga tercatat meningkat $10 \%$ dibandingkan tahun 2015. Melonjaknya produksi tersebut pada tahun 2017 disumbang dari 5 (lima) provinsi penghasil kepiting/rajungan terbesar, yaitu Sulawesi Selatan yang memiliki kontribusi $22 \%$ dari total produksi nasional, Jawa Timur 21\%, Jawa Tengah 14\%, Sumatera Utara $11 \%$, dan Jawa Barat 7\% (KKP, 2019).

Kepiting/rajungan juga memiliki peran strategis dalam sektor kelautan dan perikanan karena memiliki jumlah dan nilai ekspor tinggi dan menyerap banyak tenaga kerja pada industri pengolahan kepiting/rajungan (Khasanah, Huang, \& Asmara, 2019; Riniwati, Harahab, \& Carla, 2017). Kepiting dan rajungan yang dimaksud dalam penelitian ini terdiri atas semua jenis kepiting, rajungan dan daging kepiting (crab meat), baik dalam satuan kilogram maupun ekor yang dikonversikan ke dalam satuan kilogram. Komoditas kepiting/ rajungan yang diekspor dikelompokkan ke dalam tiga bentuk, yaitu kepiting/rajungan segar, beku, dan olahan.

Kinerja ekspor kepiting/rajungan Indonesia pada tahun 2016 dan 2017 menunjukkan bahwa terdapat penurunan volume ekspor kepiting/ rajungan karena diduga populasinya di alam mulai berkurang sehingga ada upaya mendongkrak produksi melalui usaha budidaya (Laoli, 2015; Prahadi, 2016). Namun, nilai ekspor mengalami peningkatan yang kemungkinan disebabkan karena harga jual yang lebih tinggi pada tahun 2017. Jika dilihat dari komposisinya maka dapat diketahui bahwa jenis komoditas olahan merupakan jenis yang paling banyak diekspor, yakni sekitar $54 \%$ dari seluruh komoditas kepiting/rajungan yang diekspor. Hal ini disebabkan oleh sifat kepiting/rajungan yang mudah rusak sehingga harga dan keuntungan menjadi berkurang. Untuk itu, kepiting/rajungan yang diekspor harus diproses/diolah untuk menjaga kualitas (Voldnes, Kvalvik, \& Nøstvold, 2020).
Kepiting/rajungan olahan merupakan jenis komoditas yang memiliki persentase ekspor terbesar, baik pada tahun 2016 maupun 2017 karena hampir semua kepiting/rajungan dengan kualitas first grade diekspor, sedangkan sisanya berupa rajungan dengan kualitas second grade dikonsumsi di dalam negeri (Bahtiar, Nuva, Anggraeni, \& Hidayat, 2016; Agustina, Mudzakir, \& Yulianto, 2014). Tingginya volume ekspor kepiting/ rajungan olahan mencerminkan bahwa industri olahan kepiting/rajungan masih menjadi primadona sektor usaha perikanan di Indonesia sehingga perlu dikembangkan untuk menggerakkan ekonomi nasional (Wulandari, 2018).

Secara agregat seluruh komoditas, negara tujuan utama dari eksporkepiting/rajungan Indonesia pada tahun 2017 adalah negara USA sebesar $37.71 \%$ dari total ekspor. Jika dilihat berdasarkan jenis komoditasnya maka untuk kepiting/rajungan segar paling banyak diekspor ke Singapura sebesar $34.31 \%$, untuk kepiting/rajungan beku diekspor ke USA sebesar $30.54 \%$, dan untuk kepiting/rajungan olahan diekspor ke USA sebanyak $47.70 \%$. Hal ini didorong oleh kuatnya dominasi Indonesia di pasar Amerika Serikat untuk komoditas kepiting/rajungan olahan dibandingkan negara pesaing (Fahmi, Maksum, \& Suwondo, 2015). Berdasarkan data tersebut juga dapat diketahui bahwa pasar utama produk kepiting/rajungan adalah pasar USA dan Jepang yang diikuti oleh negara di Asia Tenggara seperti Malaysia dan Singapura.

Berdasarkan latar belakang tersebut maka tampak permintaan ekspor kepiting/rajungan olahan menjadi makin dominan dibandingkan bentuk lainnya dengan pasar Amerika Serikat sebagai pasar utama. Hal ini diperkuat dengan permintaan kepiting/rajungan olahan Indonesia oleh pasar USA yang terus meningkat pada tahun 2013-2016, yaitu dari 7,998 ton pada 2013 menjadi 13,284 ton pada 2016 (UN COMTRADE, 2018). Hasil studi Oesterling (1998) menyimpulkan bahwa tingginya permintaan kepiting/rajungan olahan di USA didorong oleh tingkat harga di dalam negeri yang lebih tinggi US\$8 - US $\$ 11$ dibandingkan harga dari luar negeri.

Akan tetapi, permintaan tersebut menurun 48\% pada tahun 2017 yang hanya sebanyak 6,964 ton. Hal ini menunjukkan bahwa permintaan ekspor kepiting/rajungan bersifat fluktuatif yang disebabkan oleh faktor-faktor tertentu. Untuk itu, penelitian ini perlu dilakukan untuk menganalisis pengaruh dari harga dan faktor-faktor lainnya 
terhadap permintaan ekspor kepiting/rajungan olahan ke Amerika Serikat pada jangka pendek dan jangka panjang.

Penelitian ini dilaksanakan pada bulan Januari sampai dengan Desember 2018. Penelitian menggunakan data sekunder selama 28 tahun dari tahun 1989 sampai 2017 yang terdiri dari data volume ekspor kepiting/rajungan Indonesia ke Amerika Serikat (VXROA), volume produksi kepiting/rajungan Indonesia (VQRD), harga ekspor kepiting/rajungan Indonesia ke Amerika Serikat (PXROA), volume ekspor kepiting/ rajungan Indonesia ke Amerika Serikat pada tahun sebelumnya (VXROAt-1), dan nilai tukar Rupiah terhadap Dollar Amerika Serikat (NT). Data tersebut diperoleh dari UN-Comtrade, Kementerian Kelautan dan Perikanan (KKP), dan Badan Pusat Statistik (BPS). Pengumpulan data tersebut dilakukan melalui studi pustaka dan penelurusan internet, khususnya untuk memperoleh data perdagangan internasional.

Pada studi ini, volume ekspor dan harga ekspor merupakan variabel endogen, sedangkan variabel penjelas lainnya menjadi variabel eksogen. Hal ini berpotensi terjadi hubungan kausalitas dua arah antara variabel harga dan volume ekspor sehingga model yang dibangun berpotensi memiliki masalah endogenitas (Zhang, Kuuluvainen, Lin, Gao, \& Yang, 2017). Akibatnya, penggunaan estimator Ordinary Least Square (OLS) atau Generalized Least Square (GLS) akan bersifat bias dan tidak konsisten (Verbeek, 2017). Masalah endogenitas ini dapat diatasi salah satunya dengan cara mengganti variabel eksplanatori dengan variabel instrument. Syarat yang harus dipenuhi adalah variabel instrumen memiliki hubungan dengan variabel eksplanatori, tetapi tidak memiliki hubungan dengan error atau residual (Greene, 2018). Untuk menghadapi masalah endogenitas, pendekatan Generalized Method of Moments (GMM) dapat digunakan karena mampu menangkap potensi autokorelasi dan endogenitas pada variabel penjelas lainnya melalui penggunaan instrumental variable (IV) yang tepat (Hapsari \& Prakoso, 2016; Mulyani \& Hartono, 2018; Pramahesti \& Hartono, 2020).

Metode analisis yang digunakan adalah Metode Koreksi Kesalahan Error Correction Model (ECM). Penggunaan pendekatan ECM dalam penelitian ini didasarkan pada data penelitian yang berbentuk runtut waktu (time series) yang seringkali tidak stasioner. Data yang tidak stasioner akan menghasilkan regresi lancung atau hasil regresi yang meragukan (Granger \& Newbold, 1974). Pendekatan ECM banyak digunakan karena mampu menganalisis fenomena ekonomi jangka pendek dan jangka panjang dengan syarat utama ada hubungan kointegrasi di antara peubah penjelasnya (Engle \& Granger, 1987; Rahmawati \& Hidayat, 2017). Jika dalam jangka pendek terjadi diskontinuitas maka ECM akan memperbaikinya di periode berikutnya (de-Graft Acquah \& De-Graft Acquah, 2015). Masalah regresi lancung dapat dihindari melalui penggunaan variabel diferensiasi tetap di model ECM, tetapi tanpa menghilangkan informasi jangka panjang yang dihasilkan dari penggunaan diferensiasi data sendirian (Maghfuriyah, Azam, \& Shukri, 2019). Model pendugaan ECM selanjutnya menggunakan determinan harga dan nilai tukar sebagai faktor yang pada potensi efek merugikan dari ketidakpastian keduanya pada perdagangan yang sesuai dengan perkembangan literatur empiris. Determinan volume produksi kepiting/rajungan di dalam model pendugaan menjadi penting dalam kaitannya dengan ketersediaan bahan baku bagi industri pengolahan.

Analisis dengan menggunakan ECM meliputi tiga tahapan analisis data, yaitu (1) Uji stasioner data; (2) uji kointegrasi untuk mengetahui apakah terdapat hubungan jangka panjang antar peubah penjelas; dan (3) menyusun model ECM (Munadi, 2007). Estimasi ECM yang digunakan dalam penelitian ini adalah estimasi model Catao-Falcetti (Catão \& Falcetti, 2002) yang telah dimodifikasi. Modifikasi yang dilakukan adalah dengan mengeliminasi variabel stok kapital dan digantikan dengan variabel nilai volume produksi domestik. Model pendugaan yang digunakan pada penelitian ini adalah (Catão \& Falcetti, 2002):

$$
\begin{aligned}
\triangle L N V X R O A= & \beta_{0}+\beta_{1} \Delta L N V Q R D+\beta_{2} \Delta L N P X R O A \\
& +\beta_{3} L N V X R O A t-1+\beta_{4} \Delta L N N T+\beta_{5} \\
& E C T+\varepsilon_{t}
\end{aligned}
$$

Dimana: VXROA adalah volume ekspor kepiting/rajungan Indonesia ke Amerika Serikat (kg); VQRD adalah volume produksi kepiting/ rajungan Indonesia $(\mathrm{kg})$; PXROA adalah harga ekspor kepiting/rajungan Indonesia ke Amerika Serikat (USD/kg); VXROAt-1 adalah volume ekspor kepiting/rajungan Indonesia ke Amerika Serikat pada tahun sebelumnya $(\mathrm{kg})$; NT adalah nilai tukar Rupiah terhadap Dollar Amerika Serikat (Rp/USD); ECT adalah error correction term; $\beta_{1}-\beta_{5}$ adalah nilai koefisien dari peubah penjelas; dan $\varepsilon$ adalah error term. 


\section{FAKTOR-FAKTOR PENENTU PERMINTAAN EKSPOR PADA JANGKA PANJANG}

Sebelum dilakukan analisis (pendugaan) terhadap persamaan yang digunakan dalam model, terlebih dahulu seluruh data yang digunakan harus berada pada kondisi stasioner. Langkah yang dilakukan adalah menguji akar-akar unit untuk melihat apakah koefisien tertentu dari model autoregresif yang ditaksir memiliki nilai satu atau tidak (Widarjono, 2016). Pengujian stasioneritas menggunakan uji Augmented Dickey-Fuller (ADF) dan Phillip-Perron (PP) untuk memeriksa urutan integrasi antar variabel (Abidin et al., 2015). Hasil pengujian stasioner terhadap peubah-peubah yang digunakan dalam studi ini tertera pada Tabel 1.

Hasil uji akar-akar unit menunjukkan bahwa pada kondisi level hampir semua variabel belum stasioner, baik dengan pendekatan Augmented Dickey Fuller (ADF) maupun Phillip-Peron (PP). Akan tetapi, semua peubah telah stasioner pada kondisi first difference dengan tingkat kesalahan $1 \%$, baik dengan pendekatan ADF maupun PP. Dengan demikian dapat disimpulkan bahwa semua peubah ini dapat digunakan lebih lanjut ke persamaan permintaan ekspor kepiting/rajungan olahan Indonesia ke pasar Amerika Serikat dengan menggunakan pendekatan ECM.
Hasil estimasi dengan menggunakan estimator GMM pada Tabel 2 menunjukkan bahwa ekspor produk kepiting/rajungan olahan ke Amerika Serikat (LNVXROA) pada jangka panjang secara signifikan dipengaruhi oleh harga ekspor produk kepiting/rajungan olahan (LNPXROA $)_{t}$ ). Peubah jumlah produksi kepiting/rajungan (LNVQRD $)$ dan nilai tukar rupiah terhadap US dollar $\left(\mathrm{LNNT}_{\mathrm{t}}\right)$ tidak signifikan.

Berdasarkan hasil pengujian asumsi klasik maka model permintaan yang dibangun dapat digunakan untuk mendapatkan hasil regresi yang efisien dan tidak bias. Untuk itu, hasil analisis regresi dari persamaan fungsi permintaan jangka panjang adalah:

$$
\begin{aligned}
{L N V X R O A_{t}=} & 5.4349-0.7398 \angle N P X R O A_{t}+0.5270 \\
& L N V Q R D_{t-1}-0.2156 L N N T_{t}
\end{aligned}
$$

Dari Tabel 2 diperoleh hasil bahwa $\mathrm{R}^{2}$ $=0.8028$ yang berarti bahwa variable bebas mampu menjelaskan variansi dari variabel terkait sebesar $80.28 \%$, sedangkan sisanya $19.72 \%$ diterangkan oleh variabel lain yang tidak dimasukan dalam model. Dari hasil estimasi di atas menunjukkan bahwa tanda koefisen regresi $\angle N P X R O A_{t}, L N V Q R D_{t}$, dan $L N N T_{t}$ telah sesuai dengan tanda yang diharapkan dari teori. Dengan memperhatikan nilai J-statistik $=0.3189$ atau nilai

Tabel 1. Hasil Uji Akar-akar Unit .

Table 1. Results of Unit Roots Test.

\begin{tabular}{lcccc}
\hline \multirow{2}{*}{ Peubah/Variable } & \multicolumn{2}{c}{ Tingkat/Level } & \multicolumn{2}{c}{ Perbedaan Pertamal First Difference } \\
\cline { 2 - 5 } & ADF & PP & ADF & PP \\
\hline LNVXROA & 0.8120 & 0.5142 & $0.0000^{* * *}$ & $0.0000^{* * *}$ \\
LNPXROA & 0.8119 & 0.8561 & $0.0000^{* * *}$ & $0.0000^{* * *}$ \\
LNVQRD & 0.8854 & 0.9482 & $0.0000^{* * *}$ & $0.0000^{* * *}$ \\
LNNT & 0.1955 & 0.2096 & $0.0000^{* * *}$ & $0.0000^{* * *}$ \\
\hline
\end{tabular}

Keterangan: ${ }^{* * *}=$ Stasioner pada tingkat kesalahan $1 \% /$ Remaks: ${ }^{* * *}=$ Stationary at the level of significance is $1 \%$

Tabel 2. Hasil Estimasi Korelasi Antar Variabel pada Jangka Panjang.

Table 2. Result of Long Term Relationship Between Variables.

\begin{tabular}{lrrrr}
\hline \multicolumn{1}{c}{ Peubah/Variable } & $\begin{array}{c}\text { Koefisien/ } \\
\text { Coefficient }\end{array}$ & $\begin{array}{c}\text { Simpangan Baku/ } \\
\text { Std. Error }\end{array}$ & $\begin{array}{c}\text { t-statistik/ } \\
\text { t-Statistic }\end{array}$ & $\begin{array}{c}\text { Probabilita/ } \\
\text { Probability }\end{array}$ \\
KONSTANTA & 5.434962 & 2.553797 & 2.128189 & 0.0438 \\
LNPXROA & $-0.793795^{*}$ & 0.429610 & -1.847709 & 0.0770 \\
LNNT & -0.215606 & 0.361975 & -0.595638 & 0.5570 \\
LNVQRD & 0.527042 & 0.308518 & 1.708303 & 0.1005 \\
R-squared & 0.802798 & & & \\
Adjusted R-squared & 0.778148 & & \\
Durbin-Watson stat & 2.094455 & & \\
$\quad$ J-statistic & 0.318908 & & \\
$\quad$ Prob(J-statistic) & 0.572264 & & \\
Keterangan: ${ }^{=}$Signifikan pada $\alpha=10 \% /$ Remaks: ${ }^{*}=$ siginificant at degree of significance $\alpha=10 \% \%$ &
\end{tabular}

Keterangan: ${ }^{*}=$ Signifikan pada $\alpha=10 \% /$ Remaks: ${ }^{*}=$ siginificant at degree of significance $\alpha=10 \% \%$ 
probabilitaJ-statistik sebesar 0.5723 yang berarti tidak signifikan karena prob J-stat $>\alpha=10 \%$. Hasil ini mengindikasikan bahwa masalah endogenitas pada model telah teratasi sehingga tidak terjadi spurious regression. Uji statistik juga menunjukkan residual regresi ko-integrasi pada model tersebut stasioner. Dengan demikian, residual ko-integrasi atau kesalahan ketidakseimbangan stasioner atau I (0). Hasil estimasi dari regresi kointegrasi menunjukkan bahwa variabel-variabel harga ekspor produk kepiting/rajungan olahan, jumlah produksi kepiting/rajungan, dan nilai tukar rupiah terhadap US dolar mempunyai hubungan jangka panjang. Dengan demikian dapat dikatakan bahwa peubah yang mampu menjelaskan varian ekspor produk kepiting/rajungan olahan ke Amerika Serikat ( $\left.L N V X R O A_{t}\right)$ adalah harga ekspor produk rajungan olahan, produksi rajungan, dan nilai tukar rupiah terhadap US dollar.

Dalam jangka panjang meningkatnya harga ekspor produk kepiting/rajungan olahan ke Amerika Serikat pada tahun sebelumnya, meningkatnya produksi komoditas kepiting/rajungan pada tahun sebelumnya, meningkatnya ekspor produk kepiting/ rajungan olahan pada tahun sebelumnya, dan menurunnya nilai tukar terhadap US dollar akan mendorong peningkatan ekspor produk kepiting/ rajungan olahan ke Amerika Serikat.

\section{FAKTOR-FAKTOR PENENTU PERMINTAAN DALAM JANGKA PENDEK}

Hasil estimasi dengan menggunakan estimator GMM pada Tabel 3 menunjukkan bahwa ekspor produk kepiting/rajungan olahan ke Amerika Serikat $(\triangle L N V X R O A)$ pada jangka pendek secara signifikan dipengaruhi perubahan harga ekspor kepiting/rajungan ( $\triangle L N P X R O A)$ dan perubahan produksi kepiting/rajungan ( $L L N V Q R D)$. Peubah volume ekspor produk kepiting/rajungan olahan pada tahun sebelumnya $\left(L N V X R O A_{t-1}\right)$ dan perubahan nilai tukar rupiah terhadap US dollar $(\triangle L N N T)$ tidak signifikan. Berdasarkan hasil estimasi pada Tabel 3 maka fungsi permintaan jangka pendek dapat dituliskan sebagai berikut:

$$
\begin{aligned}
\Delta\left(L N V X R O A_{t}\right)=- & 0.4494-0.7818 \Delta L N P X R O A+ \\
& 0.5592 \Delta L N V Q R D)+0.0399 \\
& L N V X R O A(-1)-0.0097 \Delta L N N T \\
& +0.6630 E C T
\end{aligned}
$$

Dari Tabel 3 diperoleh hasil bahwa $R^{2}=$ 0.6117 yang berarti bahwa variable bebas mampu menjelaskan variansi dari variabel terkait sebesar $61,17 \%$, sedangkan sisanya $39,83 \%$ diterangkan oleh variabel lain yang tidak dimasukkan dalam model. Dari hasil estimasi di atas menunjukkan bahwa tanda koefisen regresi $\angle N P X R O A, L N V Q R D$, $\angle N V X R O A_{-1}$, dan $L N N T$ semuanya sesuai dengan tanda yang diharapkan dari teori. Dengan memperhatikan nilai J-statistik DW $=2.5116$ atau prob. J-stat lebih besar dari $\alpha=10 \%$ maka masalah endogenitas telah teratasi sehingga tidak terjadi spurious regression. Uji statistik juga menunjukkan bahwa residual regresi ko-integrasi pada model tersebut stasioner. Dengan demikian, residual ko-integrasi atau kesalahan ketidakseimbangan stasioner atau $\mathrm{I}(0)$.

Dari hasil estimasi di atas menunjukkan bahwa variabel-variabel penelitian lolos dari uji diagnosis dan koefisien ECT signifikan secara statistik dan tanda koefisien regresi sesuai dengan yang diharapkan secara teori yang membuktikan

Tabel 3. Hasil Estimasi Korelasi Antar Variabel pada Jangka Pendek.

Table 3. Result of Short Term Relationship Between Variables.

\begin{tabular}{lrcrc}
\multicolumn{1}{c}{$\begin{array}{c}\text { Peubah/ } \\
\text { Variable }\end{array}$} & $\begin{array}{c}\text { Koefisien/ } \\
\text { Coefficient }\end{array}$ & $\begin{array}{c}\text { Simpangan Baku/ } \\
\text { Std. Error }\end{array}$ & $\begin{array}{r}\text { t-Statistik/ } \\
\text { t-Statistic }\end{array}$ & $\begin{array}{c}\text { Probabilita/ } \\
\text { Probability }\end{array}$ \\
\hline KOSTANTA & -0.449412 & 2.396571 & -0.187523 & 0.8531 \\
$\Delta$ LNPXROA & $-0.781793^{* *}$ & 0.282597 & -2.766460 & 0.0116 \\
$\Delta$ LNNT & -0.009692 & 0.196260 & -0.049383 & 0.9611 \\
$\Delta$ LNVQRD & $0.559176^{*}$ & 0.278055 & 2.011024 & 0.0573 \\
LNVXROA(-1) & 0.039985 & 0.062925 & 0.635439 & 0.5320 \\
ECT & 0.663056 & 0.158665 & 4.178972 & 0.0004 \\
R-squared & 0.611728 & & & \\
Adjusted R-squared & 0.519282 & & & \\
Durbin-Watson stat & 2.010452 & & & \\
J-statistic & 2.511603 & & & \\
Prob(J-statistic) & 0.473198 & & & \\
\hline
\end{tabular}

Keterangan: ${ }^{*}=$ Signifikan pada $\alpha=10 \%$ dan ${ }^{* *}=$ Signifikan pada $\alpha=5 \% /$ Remaks: ${ }^{*}=$ siginificant at $\alpha=10 \%$ and ${ }^{* *}=$ siginificant at $\alpha=5 \%$ 
bahwa model ECM yang digunakan valid (Widyawati \& Wahyudi, 2016). Koefisien ECT bertanda positif memberikan arti bahwa eksportir kepiting/rajungan olahan ke Amerika Serikat akan melakukan penyesuaian pada periode berikutnya dengan menambah jumlah produk ekspor kepiting/rajungan olahan ke Amerika. Nilai koefisien ECT sebesar 0.6630mengindikasikan bahwa dalam jangka pendek, pasar memerlukan sekitar delapan bulan untuk mencapai keseimbangan volume ekspor kepiting/rajungan olahan ke Amerika Serikat.

\section{ELASTISITAS PERMINTAAN TERHADAP FAKTOR-FAKTOR PENENTU}

Elastisitas permintaan menggambarkan derajat kepekaan perubahan permintaan karena adanya perubahan dalam variabel bebasnya sebesar 1\% (Wahyuni, Purnastuti, \& Mustofa, 2016). Elastisitas merupakan indikator kuantitatif untuk mengukur dampak perubahan peubah penjelas terhadap permintaan suatu barang/ jasa. Nilai elastisitas dapat digunakan untuk mengevaluasi respon konsumen terhadap perubahan dari faktor-faktor penentu permintaan. Pada akhirnya, respon konsumen ini dapat secara efektif mendukung regulasi atau kebijakan yang akan diimplementasikan (Zhu, Li, Zhou, Zhang, \& Yang, 2018; Labandeira, Labeaga, \& LopezOtero, 2017). Berdasarkan hasil estimasi jangka panjang dan pendek, nilai elastisitas variabel penjelas terhadap permintaan ekspor kepiting/rajungan ke Amerika Serikat diringkas pada Tabel 4.

Berdasarkan nilai signifikansi, variabel harga ekspor dan volume produksi kepiting/rajungan di dalam negeri merupakan peubah yang memberikan pengaruh nyata terhadap permintaan ekspor kepiting/rajungan olahan ke Amerika Serikat. Peubah harga ekspor mempengaruhi permintaan pada jangka pendek dan panjang dengan nilai elastisitas yang masing-masing sebesar -0.78 dan -0.79 atau bersifat inelastis. Hal ini mengindikasikan bahwa perubahan harga tidak sepenuhnya direspon oleh negara importir karena perubahan kuantitas yang diminta masih lebih rendah dari perubahan harganya.

Sementara itu, peubah volume produksi tidak memberikan pengaruh pada jangka panjang, tetapi berpengaruh nyata pada jangka pendek dengan nilai elastisitas sebesar 0.53 sehingga permintaannya bersifat inelastis terhadap volume ekspor. Hal ini mengindikasikan bahwa ketersediaan bahan baku untuk industri produk olahan dari kepiting/rajungan di dalam negeri cenderung sama pada jangka pendek. Untuk itu, perlu dilakukan perbaikan sistem logistik agar ketersediaan bahan baku terjamin sehingga produksi kepiting/rajungan di dalam negeri dapat berjalan secara kontinyu bagi industri pengolahan sehingga permintaan ekspor dapat terpenuhi. Ketersediaan produksi bahan baku juga tidak terlepas dari kestabilan harga di tingkat nelayan karena harga jual yang anjlok dapat menurunkan produksi kepiting/rajungan (Maulana, 2015).

\section{SINTESA KEBIJAKAN}

Model permintaan ekspor kepiting/rajungan olahan yang dihasilkan telah menjawab tujuan penelitian ini. Hasil penelitian menunjukkan bahwa faktor-faktor yang menentukan permintaan ekspor kepiting/rajungan olahan Indonesia ke Amerika Serikat adalah produksi, harga ekspor, nilai tukar Rp/US\$, dan lag ekspor. Namun demikian, produksi kepiting/rajungan di dalam negeri menjadi faktor yang pengaruhnya terbesar bagi model permintaan kepiting/rajungan olahan ke Amerika Serikat pada jangka pendek. Faktor lain yang juga memiliki pengaruh nyata terhadap permintaan ekspor kepiting/rajungan olahan ke Amerika Serikat adalah harga ekspor, baik pada jangka pendek maupun jangka panjang.

Elastisitas permintaan ekspor kepiting/ rajungan olahan ke Amerika Serikat terhadap perubahan harga bersifat inelastis, baik pada jangka pendek maupun jangka panjang. Hal ini mengindikasikan bahwa perubahan harga tidak sepenuhnya direspon oleh importir karena perubahan kuantitas yang diminta masih lebih rendah dari perubahan harganya. Elastistas

Tabel 4. Elastisitas Permintaan Terhadap Variabel Penjelas. Table 4. Demand Elasticity for Explanatory Variables.

\begin{tabular}{lcc}
\multirow{2}{*}{ Peubah/Variables } & \multicolumn{2}{c}{ Nilai Elastisitas/Elacticity } \\
\cline { 2 - 3 } & Jangka Pendek/Short Term & Jangka Panjang/Long Term \\
\hline PXROA & -0.7818 & -0.7938 \\
$V Q R D$ & 0.5592 & 0.5270 \\
\hline
\end{tabular}


permintaan kepiting/rajungan olahan ke Amerika Serikat terhadap produksi kepiting/rajungan di dalam negeri bersifat elastis pada jangka pendek dan menjadi inelastis pada jangka panjang. Hal ini mengindikasikan bahwa ketersediaan produk olahan dari kepiting/rajungan di dalam negeri masih belum stabil pada jangka pendek, sedangkan pada jangka panjang produksi telah berjalan dengan baik sehingga kontinuitas produksi terjaga dengan baik pula

\section{IMPLIKASI KEBIJAKAN}

Hasil penelitian menggarisbawahi pentingnya daya saing untuk memfasilitasi ekspor kepiting/ rajungan olahan. Untuk menghadapi guncangan eksternal dalam jangka pendek, stabilitas harga ekspor dapat membantu meningkatkan permintaan ekspor melalui instrumen nilai tukar yang dijadikan sebagai peredam guncangan eksternal. Sementara dalam jangka panjang, permintaan ekspor kepiting/rajungan olahan dapat ditingkatkan dengan menjaga keberlanjutan produksi kepiting/rajungan sebagai bahan baku bagi industri pengolahan. Selain bahan baku, upaya lain yang dapat dilakukan antara lain melalui usaha nelayan dengan meningkatkan efisiensi produksi dan meningkatkan penggunaan teknologi agar biaya produksi dapat ditekan sehingga harga ekspor kepiting/rajungan olahan Indonesia dapat bersaing dengan negara pengekspor utama lainnya.

Langkah strategis yang dapat dirumuskan adalah terkait stabilitas harga dan perbaikan sistem logistik. Langkah pertama, pemerintah pusat dan daerah perlu berupaya menjaga kestabilan harga jual kepiting/rajungan olahan ke pasar Amerika Serikat pada jangka panjang. Upaya yang dapat dilakukan antara lain dengan meningkatkan efisiensi produksi dan meningkatkan penggunaan teknologi agar biaya produksi dapat ditekan sehingga harga ekspor kepiting/rajungan olahan Indonesia dapat bersaing dengan negara pengekspor utama lainnya. Langkah kedua, pemerintah pusat dan daerah perlu memperbaiki sistem logistik melalui mekanisme foodchain agar ketersediaan bahan baku terjamin sehingga produksi kepiting/rajungan di dalam negeri dapat berjalan secara kontinyu. Mekanisme foodchain ini akan menjamin ketersediaan bahan baku bagi industri pengolahan kepiting/rajungan sehingga permintaan ekspor dapat terpenuhi, khususnya pada jangka pendek.

\section{UCAPAN TERIMAKASIH}

Penulis mengucapkan terima kasih kepada Balai Besar Riset Sosial Ekonomi Kelautan dan Perikanan yang telah memfasilitasi pelaksanaan kegiatan penelitian untuk menghasilkan karya tulis ilmiah ini. Penulis juga mengucapkan terima kasih kepada Badan Karantina Ikan, Pengendalian Mutu dan Keamanan Hasil Perikanan (BKIPM), Kementerian Kelautan dan Perikanan yang banyak membantu terkait dengan pengadaan data bagi penelitian ini.

\section{PERNYATAAN KONTRIBUSI PENULIS}

Kontributor dalam karya tulis ilmiah adalah Estu Sri Luhur sebagai kontributor utama dan Asnawi, Freshty Yulia Arthatiani, dan Siti Hajar Suryawati sebagai kontributor anggota yang sudah disepakati bersama-sama untuk diketahui semua pihak yang berkepentingan.

\section{DAFTAR PUSTAKA}

Abidin, I. S. Z., Haseeb, M., Azam, M., \& Islam, R. (2015). Foreign direct investment, financial Development, international trade and energy consumption: Panel data evidence from selected ASEAN Countries. International Journal of Energy Economics and Policy, 5(3), 841-850.

Agustina, E.R., Mudzakir, A.K., \& Yulianto, T. (2014). Analisis Distribusi Pemasaran Rajungan (Portunus Pelagicus) di Desa Betahwalang Kabupaten Demak. Journal of Fisheries Resources Utilization Management and Technology, 3(3), 190-199. https://ejournal3.undip.ac.id/index.php/jfrumt/ article/view/5543.

Bahtiar, R., Nuva, Anggraeni, D., \& Hidaya, N.K. (2016). Economic evaluation of implementing minimum legal size on blue swimming crab fishery in Indonesia. Marine and Coastal Ecosystem Valuation, Institution, and Policy in Southeast Asia, 341-363. https://doi.org/10.1007/978-98110-0141-3 17 .

[BKIPM] Badan Karantina Ikan, Pengendalian Mutu, dan Keamanan Hasil Perikanan. (2018). Data Operasional BKIPM Tahun 2016 dan 2017. Jakarta, ID: Badan Karantina Ikan, Pengendalian Mutu, dan Keamanan Hasil Perikanan, Kementerian Kelautan dan Perikanan.

Catão, L. \& Falcetti, E. (2002). Determinants of Argentina's External Trade. Journal of Applied Economics, 5(1), 19-57. https://doi.org/10.1080/ 15140326.2002.12040570.

de-GraftAcquah, H., \& Acquah, J.D. (2015). An application of the error correction model in analyzing the long run equilibrium between Ghana's exports 
and imports. APSTRACT: Applied Studies in Agribusiness and Commerce, 9(3), 57-62. DOI: 10.19041/APSTRACT/2015/3/8.

Engle, R.F. \& Granger, C.W.J. (1987). Co-integration and error correction: representation, estimation, and testing. Econometrica, 55(2), 251-276. DOI: 10.2307/1913236.

Fahmi, A.S., Maksum, M. \& Suwondo, E. (2015). USFDA import refusal and export competitiveness of Indonesian crab in US market. Agruculture and Agricultural Science Procedia, 3(2015), 226-230. DOI: 10.1016/j.aaspro.2015.01.044.

Granger, C.W.J. \& Newbold, P. (1974). Spurious Regressions in Econometrics. Journal of Econometrics, 2(2), 111-120. https://doi. org/10.1016/0304-4076(74)90034-7.

Greene, W.H. (2018). Econometric Analysis, $8^{\text {th }}$ edition. New York, US: Prentice Hall.

Hapsari, R.D. \& Prakoso, I. (2016). Penanaman Modal dan Pertumbuhan Ekonomi Tingkat Provinsi di Indonesia. Jurnal Ekonomi dan Bisnis, 19(2), 211-224. https://doi.org/https://doi.org/10.24914/ jeb.v19i2.554.

Khasanah, U., Huang, W.C., \& Asmara, R. (2019). Indonesian frozen and processed crab export performance and competitiveness analysis. Agricultural Socio-Economics Journal, 19(3), 165-171. DOI: http://dx.doi.org/10.21776/ ub.agrise.2019.019.3.5.

[KKP] Kementerian Kelautan dan Perikanan. (2019). Statistik KKP, Produksi Perikanan. Retrieved fromhttps://statistik.kkp.go.id/home php?m=total\&i=2.

Labandeira, X., Labeaga, J.M., \& Lopez-Otero, X. (2017). A meta-analysis on the price elasticity of energy demand. Energi Policy, 102(2017), 549-568. DOI: http://dx.doi.org/10.1016/j. enpol.2017.01.002.

Laoli, N. (2015). Populasi susut, ekspor kepiting dan rajungan turun. Kontan.co.id Senin, 11 Mei 2015 /17:05 WIB. Retrieved from https://industri. kontan.co.id/news/populasi-susut-ekspor-kepiting-dan-rajungan-turun, diakses tanggal 24 November 2016.

Maghfuriyah, A., Azam, S.M.F., \& Shukri, S. (2019). Market structure and Islamic banking performance in Indonesia: An error correction model. Management Science Letter, 9(9), 1407-1418. DOI: 10.5267/j.msl.2019.5.010.

Maulana, A. G. (2015). Permintaan Ekspor Berkurang, Harga Rajungan Anjlok. Bisnis.com: 28 September 2015 21:35 WIB. Retrieved from http://industri.bisnis.com/read/20150928/ 99/476800/permintaan-ekspor-berkurang-harga-rajungan-anjlok, diakses tanggal 24 November 2016.
Mulyani, D. \& Hartono, D. (2018). Pengaruh Efisiensi Energi Listrik pada Sektor Industri dan Komersial terhadap Permintaan Listrik di Indonesia. Jurnal Ekonomi Kuantitatif Terapan, 11(1), 1-17. Doi: https://doi.org/10.24843/ JEKT.2018.v11.i01.p01.

Munadi, E. (2007). Penurunan pajak ekspor dan dampaknya terhadap ekspor minyak kelapa sawit Indonesia ke India (pendekatan error correction model). Informatika Pertanian, 16(2), 1019-1036. DOI: 10.30908/bilp.v1i3.303.

Oesterling, M.J. (1998). "Blue" crab resources in other countries: implications for the US industry. Journal of Shellfish Research, 17(2), 375-378. https://scholarworks.wm.edu/ vimsarticles/493.

Prahadi, Y.Y. (2016). Dongkrak Ekspor, Pemerintah Galakkan Budidaya Rajungan dan Kepiting. SWA 21 Oktober 2016. Retrieved from https:// swa.co.id/swa/business-strategy/dongkrakekspor-pemerintah-galakkan-budidaya-rajungan-dan-kepiting, diakses tanggal 24 November 2016.

Pramahesti, K., \& Hartono, D. (2020). Energy, Economic Growth, and Financial Development in ASEAN+3. Signifikan: Jurnal Ilmu Ekonomi, 9(1), 137-152. Doi: http://dx.doi.org/10.15408/ sjie.v9i1.13536.

Rahmawati, D.A.D \& Hidayat R, W. (2017). Analisis pengaruh suku bunga Sertifikat Bank Indonesia dan Jumlah uang beredar terhadap tingkat inflasi di Indonesia periode 2006. 1-2015.12 (pendekatan error correction model). Jurnal IImu Ekonomi, 1(1), 60-74.http://ejournal. umm.ac.id/index.php/jie/article/view/5409/5235.

Riniwati, H., Harahab, N., \& Carla, T.Y. (2017). Analysis of Indonesian crab export competitiveness in international market. International Review of Management and Marketing, 7(5), 23-27. https:// www.econjournals.com/index.php/irmm/article/ view/5576/pdf.

UN COMTRADE. (2018). United Nations commodities trade statistics database. https://comtrade. un.org/data/.

Verbeek, M. (2017). A Guide to Modern Econometrics, 5th edition. New York, US: John Wiley \& Sons.

Voldnes, G., Kvalvik, I., \& Nøstvold. (2020). Taking care of a highly valuable resource throughout the value chain - Lack of market orientation in red king crab ecport? Marine Policy, 117(2020), Article 103965. https://doi.org/10.1016/j. marpol.2020.103965.

Wahyuni, D., Purnastuti, L., \& Mustofa, M. (2016). Analisis elastisitas tiga bahan pangan sumber protein hewani di Indonesia. Jurnal Economia, 12(1), 43-53. Doi:10.21831/economia. v12i1.9544. 
Widarjono, A. (2016). Ekonometrika Teori dan Aplikasinya. First Edition. Yogyakarta: Ekonisia.

Widyawati, S. \& Wahyudi, S.T. (2016). Determinan pertumbuhan kredit modal kerja perbankan di Indonesia: Pendakatan error correction model (ECM). Jurnal Keuangan dan Perbankan, 20(1), 149-156, http://jurnal.unmer.ac.id/index.php/jkdp/ article/view/159/pdf.

Wulandari, A. (2018). Quality control strategy on crab handling process by using Analytical Hierarchy Process Method. Agricultural Science, 1(2), 93-103. http://agriscience.scientific-work.org/ index.php/agriscience/article/view/10.

Zhang, H., Kuuluvainen, J., Lin, Y., Gao, P., \& Yang, H. (2017). Cointegration in China's log import demand: price endogeneity and structural change. Journal of Forest Economics, 27(2017), 99-109. http://dx.doi.org/10.1016/j.jfe.2017.03.003.

Zhu, X., Li, L., Zhou, K., Zhang, X., \& Yang, S. (2018). A meta-analysis on the price elasticity and income elasticity of residential electricity demand. Journal of Cleaner Production, 201(2018), 169-177. DOI: https://doi.org/10.1016/j. jclepro.2018.08.027. 